CSI. B. Johannessen (ed.), Language Variation Infrastructure, Oslo Studies in Language 3(2), 2011.

\title{
AGGREGATE ANALYSIS OF VOWEL PRONUNCIATION IN SWEDISH DIALECTS
}

\author{
THERESE LEINONEN \\ Society of Swedish Literature in Finland
}

\section{A B S T R ACT}

In this paper an aggregate analysis of vowel pronunciation in Swedish dialects is proposed by means of multidimensional scaling (MDS). The Gap statistic showed that no statistically significant partitioning of Swedish dialects can be made based on vowel pronunciation, which means that the dialects form a true linguistic continuum. Vowels recorded by 1,170 speakers at 98 sites were analyzed acoustically with principal components of Barkfiltered spectra, and the linguistic distances between varieties were computed as the Euclidean distance of the acoustic variables. The MDS analyses showed that the dialect areas that can be detected based on vowel pronunciation in modern rural varieties of Swedish largely correspond to the traditional Swedish dialect division and divisions of regional varieties of Standard Swedish. The results also show a large-scale ongoing dialect leveling. The change is largest in many central parts of the language area close to the biggest cities, while the dialects in more peripheral areas are relatively stable.

\section{[1] INTRODUCTION}

The Swedish dialects have gone through massive leveling in the latter half of the 20th century (Hallberg 2005; Thelander 2005). Due to a societal change from rural societies to urban life style, including migrations from the countryside to towns and cities, traditional rural dialects have disappeared in many parts of the language area and been replaced by (regional varieties of) Standard Swedish. In this leveling process especially morphological, syntactical and lexical variation has decreased profoundly. Phonetic and prosodic features are assumed to have been preserved to a larger degree (Engstrand et al. 1997).

Figure 1 on page 77 shows the traditional division of Swedish rural dialects by Wessén (1969). According to Wessén $(1969,12-13)$, the rural Swedish dialects have formed a continuum without any sharp dialect borders. In this continuum, however, Wessén identified six main dialect areas: South Swedish dialects (sydsvenska mål), Götaland dialects (götamål), Svealand dialects (sveamål), Norrland dialects (norrländska mål), Gotland dialects (gotländska mål), and Finland-Swedish dialects (östsvenska mål). 
Elert (1994) proposed a division of the regional varieties of Standard Swedish. He based the division mainly on sentence intonation and differences in vowel pronunciation. The geographic division by Elert largely resembles the classification of the traditional rural dialects by Wessén (1969).

In order to make instrumental analysis of variation in modern rural varieties of Swedish possible, dialect data was recorded at a large number of sites around year 2000 in the project SweDia (see below, Section [2]). Based on SweDia data, Bruce (2004) classified Swedish dialects according to intonational variation. The intonational parameters of the model were focal accentuation, phrasing, word accentuation and compounding. Seven distinct dialect regions were identified, largely corresponding to the ones found by Wessén and Elert.

Both rural Swedish dialects and regional varieties of Standard Swedish vary a lot when it comes to vowel pronunciation, and vowels have been important for characterizing varieties of Swedish and classifying dialects (Bruce 2010,102-103). Still, only very few instrumental analyses of vowels covering the whole Swedish language area exist. In this paper the variation in vowel pronunciation in modern rural varieties of Swedish is analyzed by means of acoustic analysis of vowels recorded at nearly 100 sites in Sweden and the Swedish-speaking parts of Finland. The speakers represent two different age-groups which makes the study of language change in apparent time possible.

Aggregating methods introduced by the dialectometric research tradition (Nerbonne 2009) are used for identifying geographic dialect areas and studying ongoing change in this paper. Aggregation originally developed as a more objective alternative to the isogloss method for defining dialect areas and exploring dialect continua. While isoglosses are chosen subjectively by the researcher, aggregating methods can incorporate much larger amounts of data simultaneously and also deal with conflicting signals in the data.

\section{[2] DATA}

The data analyzed in this paper were recorded within the SweDia project (Eriksson 2004), a collaboration between the universities of Lund, Stockholm and Umeå. The data were gathered during the period 1998-2001 at 98 rural sites (see Figure 1 on the next page) in the Swedish language area. The locations were chosen to represent the dialectal situation in the Swedish language area by being balanced geographically and with respect to population density. At each location recordings were made with around twelve speakers: three older women, three older men, three younger women and three younger men. The older speakers were in the approximate age range of 55-75 years when the recordings were made, and the younger speakers were $20-35$ years. The total number of speakers included in the analyses in this paper is 1,170 .

Vowel segments were elicited with mono- or bi-syllabic words. To keep the 


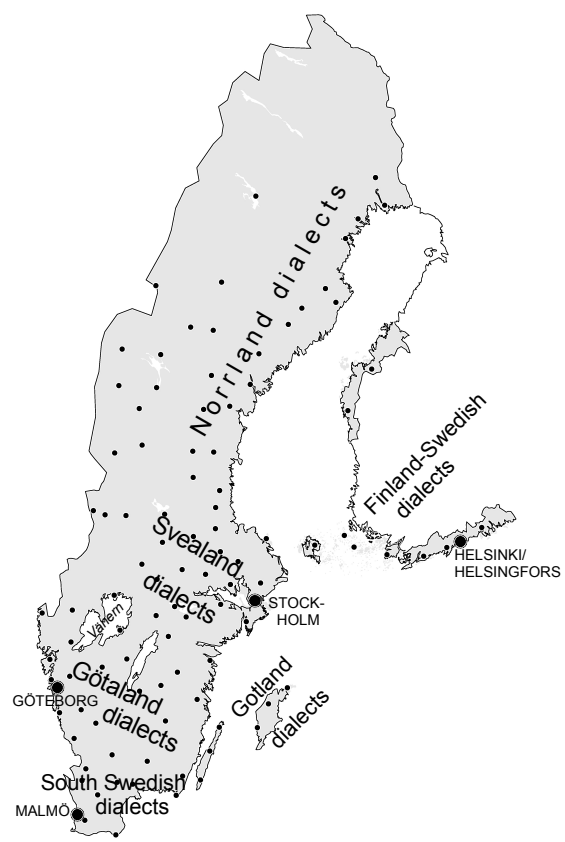

FIGURE 1: The traditional Swedish dialect areas according to Wessén (1969), and the 98 data sites of the current study. The four biggest cities in the area are included as reference points in the map. 
phonetic context of the vowels as stable as possible, the target vowels were surrounded by coronal consonants. For the current study the vowels from the stressed syllables in the following 19 words were used (Standard Swedish vowel pronunciation in square brackets): dis [i:], disk [I], dör [œ:], dörr [œ], flytta [y], lass [a], lat [a: ], leta [e:], lett [ẹ], lott [o], lus [ษ:], lås/låt [o:], lär [æ:], lös [ø:], nät [ع:], sot [u:], särk $[æ]$, söt $[\varnothing \mathrm{x}]$, typ $[\mathrm{y}:]$.

The data set includes all of the Standard Swedish long vowel phonemes. In addition the allophonic variants of $/ \varepsilon: /$ and $/ \varnothing_{:} /([æ:]$ and [œ:] which occur only before $/ r /$ ), and a few vowels which reflect language historical developments are included. For example, the words lös and söt have the same vowel phoneme in Standard Swedish, but historically the former originates from a diphthong /au/, which has been monophthongized in most varieties of Swedish, while the latter one is an original monophthong. Some of the Swedish dialects have preserved these vowels as two different phonemes. The phoneme /o:/ was elicited with the word las in some sites and the word lat in others. Of the Standard Swedish short vowel phonemes a few are missing because they had not been consistently elicited at all sites for the database. Even though a few short vowel phonemes are missing, the data should be able to give a good picture of how the Swedish dialects relate to each other with respect to vowel pronunciation. The variation in vowel pronunciation across varieties of Swedish has been described to be more prominent in long vowels than in short vowels (Elert 2000, 38).

A few sites which are well known for their well-preserved divergent rural dialects (Orsa and Älvdalen) have been excluded from the current analysis. This is because they were considered so different from other dialects during the SweDia fieldwork that a completely different word list was used for eliciting vowel sounds in these dialects. Hence, there is no directly comparable vowel data from these dialects in the SweDia database.

The recordings were made in the speakers' homes or other familiar places in order to make the participants feel comfortable and to make the use of the local vernacular feel natural. A lapel microphone and a portable DAT-recorder were used, and the recordings were done at $48 \mathrm{kHz}$ sample rate and 16-bit amplitude resolution. Before analysis the data were downsampled to $16 \mathrm{kHz} / 16$ bit. Each speaker repeated the words 3-5 times. The recordings were annotated and the vowels manually segmented within the SweDia project.

\section{[3] METHODS}

\section{[3.1] Acoustic analysis}

All vowel segments were filtered with Bark filters up to 18 Bark at nine equidistant sampling points within each segment with a window length of $13 \mathrm{~ms}$. The first sampling point was at $25 \%$ of the total vowel duration and the last at $75 \%$. The Bark-filtered spectra were level-normalized for every $13 \mathrm{~ms}$ sample so that 
the levels add up to $80 \mathrm{~dB}$. A representation in Bark filters gives a good perceptual representation of vowels, because the Bark scale corresponds to the critical bandwidth of human hearing.

After the Bark-filtering each sampling point of each vowel pronunciation was characterized by the levels (in $\mathrm{dB}$ ) in the consecutive frequency filters. Since the speakers had repeated the 19 different vowels 3-5 times the average levels of these repetitions were computed for each speaker.

The Bark-filtered data were subsequently reduced to two principal components (PCs) by principal component analysis (PCA) with varimax rotation. PCA is a data reduction technique that aims at reducing a larger number of variables into a smaller set of components by combining variables that correlate with each other (Tabachnik \& Fidell 2007). Reducing a filter bank representation of speech samples to PCs leads to an articulatory meaningful configuration. PC1 is related to vowel height, while PC2 is related to tongue advancement. PCs of Bark-filtered vowel spectra have been shown to correlate highly with formant measurements by Jacobi (2009) and Leinonen (2010). The method is well-suited for large-scale analysis of vowel pronunciation because it is more reliably automatable than formant measurements, which always need to be manually corrected.

Following Jacobi (2009) only point vowels were used for building up the PCA, which means that all articulatory dimensions are represented equally. For the Swedish data the vowels transcribed as [i:], [æ:], [a: ]/[a:] and [u:] in the database were chosen for calculating the loadings in the initial phase of the PCA.

Because of the anatomical/physiological differences between male and female vocal tracts (men have on average longer vocal tracts than women) the formants related to vowel production have higher frequencies in female voices than in male voices (Peterson \& Barney 1952). These differences can be normalized for by applying PCA separately to data from male speakers and females speakers (Leinonen 2010). Vowels produced by male speakers were analyzed in the frequency range 2-17 Bark, while vowels produced by female speakers were analyzed at 3-18 Bark.

In the initial phase of the PCA point vowels from 230 women and 230 men were used for computing loadings. Subsequently PC scores were computed for all vowels of all speakers. In the male analysis PC 1 explains $41.1 \%$ of the total variance in the data and in the female analysis PC1 explains $41.4 \%$ of the variance. PC2 explains $36.3 \%$ (male) respectively $36.8 \%$ (female) of the variance. Together the two extracted components explain nearly $80 \%$ of the variance in both analyses. For a more detailed description of the acoustic analysis see Leinonen (2010).

\section{[3.2] Analysis of dialectal variation}

Common aggregating techniques used in dialectometric research for exploring dialect areas and dialect continua are cluster analysis and multidimensional scaling (MDS). In both methods a distance matrix with the aggregate pairwise distances 
between all objects is used as input. MDS is a method for reducing complex distance data to interpretable low-dimensional representations, while cluster analysis produces partitions of the data. MDS is suitable for visualizing dialect continua, while cluster analysis detects dialect groups.

The Gap statistic can be used for estimating the number of significant clusters produced by any clustering algorithm (Tibshirani et al. 2001). Lundberg (2005) used the Gap statistic to estimate the number of significant clusters when grouping the Swedish dialects based on acoustic analysis of the vowel in the word lat (/a:/ in Standard Swedish) and found three significant clusters. The Gap statistic was applied to the present data set, and the analysis showed that there are no well separated clusters. This result indicates that the Swedish dialects form a true continuum when it comes to an aggregate analysis of vowel pronunciation.

Clustering methods could be applied to the data, but they are likely to produce unstable results, since any sharp division into subsets is not in agreement with the structure of the data. Therefore MDS was chosen for analyzing the dialectal variation in vowel pronunciation in this paper. The MDS plots (for example, Figure 2 on page 82) confirm that the Swedish language area can be best described as a dialect continuum when it comes to vowel pronunciation.

In MDS, original distances between objects are approximated in a low-dimensional space by an iterative algorithm (Jain \& Dubes 1988). A number of algorithms for MDS have been proposed. In a study of the linguistic distances between varieties of Dutch, Heeringa (2004) measured the fitness of three different MDS procedures by correlating the original distances with the Euclidean MDS coordinatebased distances, and found that Kruskal's non-metric MDS gave the best results. In this paper Kruskal's non-metric MDS, as implemented in the RuG/L04 ${ }^{1}$ software, was used.

For the MDS the distances between the varieties were calculated as the average distance of the 19 vowels in the data set. First, the distance for each vowel between two varieties was calculated as the Euclidean distance of the acoustic variables of vowel quality (Equation 1), that is, the two PCs measured at nine sampling points within each vowel segment, starting at $25 \%$ of the total vowel duration and ending at $75 \%$. Subsequently, the average of the vowel distances was calculated. For some groups of speakers a few of the vowels are missing, and the distances involving these objects are the average distances of a fewer number of vowels. At least 15 of the 19 vowels were recorded in each speaker group.

The equation below shows the Euclidean distance, where $i$ ranges over the nine sampling points per vowel and $x$ and $y$ are either two different sites (Section [4.1]) or two different speaker groups (older or younger speakers at any of the sites, Section [4.2]):

[1] RuG/L04 - software for dialectometrics and cartography. By P. Kleiweg, University of Groningen. $<$ http://www.let.rug.nl/kleiweg/L04/> 


$$
\operatorname{distance}(x, y)=\sqrt{\sum_{i=1}^{9}\left(\left(P C 1_{x i}-P C 1_{y i}\right)^{2}+\left(P C 2_{x i}-P C 2_{y i}\right)^{2}\right)}
$$

When applying MDS to dialect data three dimensions generally explain at least around $90 \%$ of the total variance in the data (for example, Heeringa 2004; Prokić \& Nerbonne 2008), which means that additional dimensions are not important for describing the dialectal variation. In MDS to three dimensions positions in a three-dimensional space are assigned to all varieties included in the analysis. One way of displaying the results is to plot the objects in a Cartesian coordinate system. The closer to each other two objects are in the coordinate system the smaller the linguistic difference. However, the interpretation of the results of MDS is facilitated if the results can be viewed in relation to geography. By using the maprgb function in the RuG/L04 software, which uses the RGB color model, the results of MDS can be displayed on maps (Nerbonne et al. 1999). By using the RGB color model all positions in the three-dimensional MDS space are translated to a distinct color. The amount of red represents the first dimension of the MDS, the amount of green the second dimension and the amount of blue the third dimension. Coloring the area surrounding each site on a map with the color corresponding to the position assigned by MDS links the results of MDS to geography.

\section{[4] RESULTS}

Below the results of MDS applied to two different divisions of the data are presented. In Section [4.1] the geographic variation is described by averaging over all speakers per site. In Section [4.2] the data is split into older and younger speakers per site in order to analyze the degree of language change in apparent time. Group means of the speakers were calculated for PC1 and PC2 respectively for each of the 19 vowels at the nine sampling points. Subsequently the Euclidean distances between varieties were calculated based on the group means, and the resulting distance matrix was analyzed with MDS.

\section{[4.1] Geographic dialect continuum}

In the first MDS analysis, average values for each site (that is, the averages of the approximately twelve speakers) were calculated for the acoustic variables before measuring the linguistic distances between sites and applying MDS. The distance matrix comprised the pairwise distances between all 98 sites.

Figure 2 on the next page shows the results of the MDS in a two-dimensional coordinate system where the color of the dot represents the third dimension. One dimension explains $81.4 \%$ of the variance, two dimensions $93.6 \%$ and three dimensions $96.3 \%$. It is clear that the first dimension already explains a very large part 


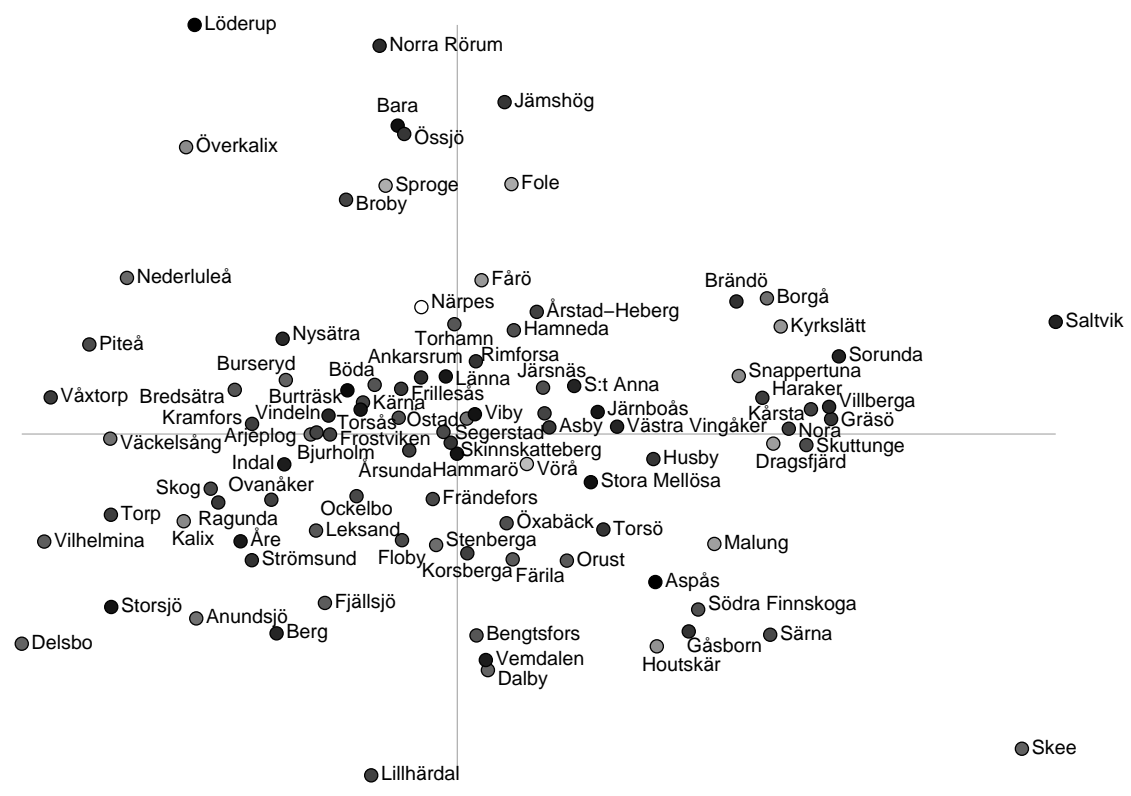

FIGURE 2: Results of MDS to 3 dimensions of the linguistic distances between sites. The 1st dimension is represented by the $\mathrm{x}$-axis, the 2 nd dimension by the $\mathrm{y}$-axis and the $3 \mathrm{rd}$ dimension by the gray-scale color of the dot. Because of the density of sites close to the origin, a few labels have been omitted. 


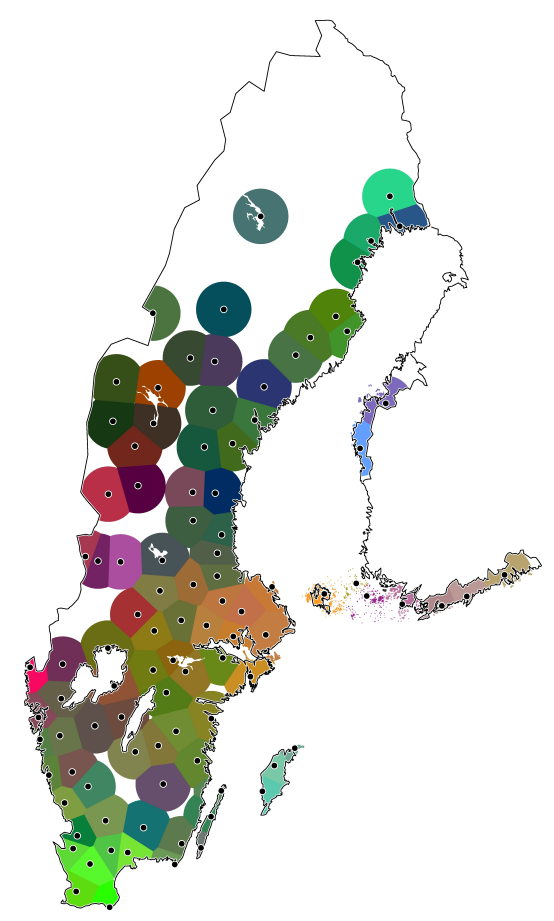

FIGURE 3: Results of MDS to 3 dimensions of the linguistic distances between sites, displayed with the RGB color model.

of the variance. Using more than three dimensions would only mean a small improvement of the variance explained. The plot does not show any clear clusters of sites, but there is only one big cloud, which supports the result of the Gap statistic that the dialects form a true continuum. The plot shows a concentration of sites close to the origin and a more sporadic distribution in the peripheries.

In the first dimension, sites in Svealand (mainly the province Uppland) and on the Finnish south coast have high values, while mainly sites in Norrland have low values. Sites with high values on the second dimension are the South Swedish ones, but also the ones on Gotland. The third quadrant (negative values on the two first dimensions) is dominated by sites in Norrland. Skee is an outlier in the corner of the fourth quadrant (positive values on the first dimension and negative on the second). In the fourth quadrant other sites close to the Norwegian border are also found. The third dimension separates sites on the Finnish south coast (light) from the ones in Uppland (dark), and the Gotlandic (light) from the South Swedish ones (dark). Närpes has an extremely high value (white) in the third dimension.

Figure 3 displays the results of the MDS on a map using the RGB color model, which enables interpretation of the results even without any knowledge of the 


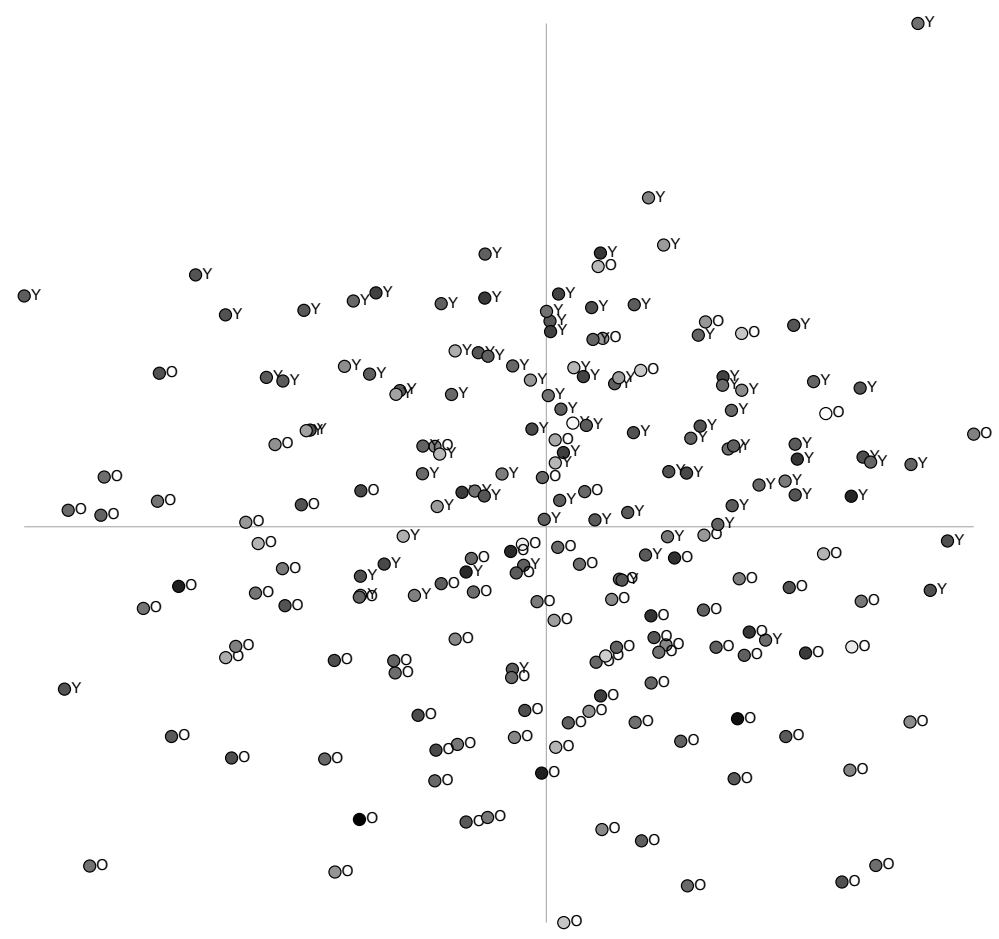

FIGURE 4: Results of MDS to 3 dimensions of the linguistic distances between sites and age groups. The 1st dimension is represented by the $\mathrm{x}$-axis, the $2 \mathrm{nd}$ dimension by the $y$-axis and the 3rd dimension by the color of the dot. $\mathrm{O}=$ older speakers, $\mathrm{Y}=$ younger speakers .

geographic positions of the Swedish village names. In this map, the southernmost province, Skåne, forms a very coherent area with low values in the first and third dimensions and high values in the second dimension leading to green color. The separation of the South Swedish varieties from the ones on Gotland in the third dimension can be seen in colors close to cyan on Gotland. Uppland is also a very coherent area with orange color. Red and purple colors are found mostly close to the Norwegian border. In Norrland mostly dark green colors are found, but also other dark colors and blue. Götaland is quite incoherent with different colors from the center of the color spectrum. In Finland there is a clear difference between the sites on the south coast and the west coast.

The map shows that even if the distribution of dialectal features is continuous, some more coherent dialect areas can be detected. 


\section{[4.2] Dialect leveling}

In the following step age-related variation was analyzed in addition to the geographic variation. The distance matrix that MDS was applied to comprised the pairwise linguistic distances between 196 objects (2 age groups $\times 98$ sites). One dimension explains $78.9 \%$ of the variance, two dimensions $92.3 \%$ and three dimensions $95.9 \%$.

Figure 4 on the preceding page shows the results of the MDS in a two-dimensional coordinate system where the color of the dot represents the third dimensions. The objects form one big cloud, except for one outlier, which for some reason has an extremely high value in the second dimension. This outlier is the younger speakers of Löderup (South Sweden). The labels of the objects do not fit into the plot, but for each object a letter indicates whether the dot concerns older or younger speakers. As can be seen, the second dimension mainly seems to separate the two age groups. The older speakers mostly have low values in the second dimension, while younger speakers have high values.

The maps in Figure 5 on the following page display the three dimensions of the MDS of older and younger speakers per site using the three-dimensional RGB color spectrum. The extremely high value of the younger speakers of Löderup in the second dimension would mean that a large proportion of the color representing the second dimension would be required for representing this variety. In order to produce more separation between the other varieties the young speakers of Löderup were left out of the color visualization. The two age groups are displayed on separate maps, but the colors of the two maps are comparable since they are based on one single MDS analysis.

The difference between the map of the older speakers and the map of the younger speakers is striking. In the map of the older speakers a broad spectrum of colors is found, while the map of the younger speakers is dominated by green. This shows a large-scale on-going leveling of the Swedish dialects. The dialect leveling can be confirmed statistically. The average linguistic distance between sites is larger for the older speakers than for younger speakers. This difference is statistically significant (Paired Samples t-test, $t(4752)=30.1, p<0.001)$.

By comparing the colors of older and younger speakers in Figure 5 on the next page conclusions can be drawn about in which dialects vowel pronunciation is changing the most. For example, the sites in Finland have much more similar colors for older and younger speakers than many of the sites in Sweden. In order to get a more apparent view of which dialects that seem to be changing and which are stable, a map visualizing only the within site distances was created. The sites were divided into three groups using K-means clustering (the most commonly used clustering algorithm for partitioning data; the user decides how many groups should be formed, and the algorithm partitions the most similar items into groups by minimizing the total error sum of squares; Legendre \& 


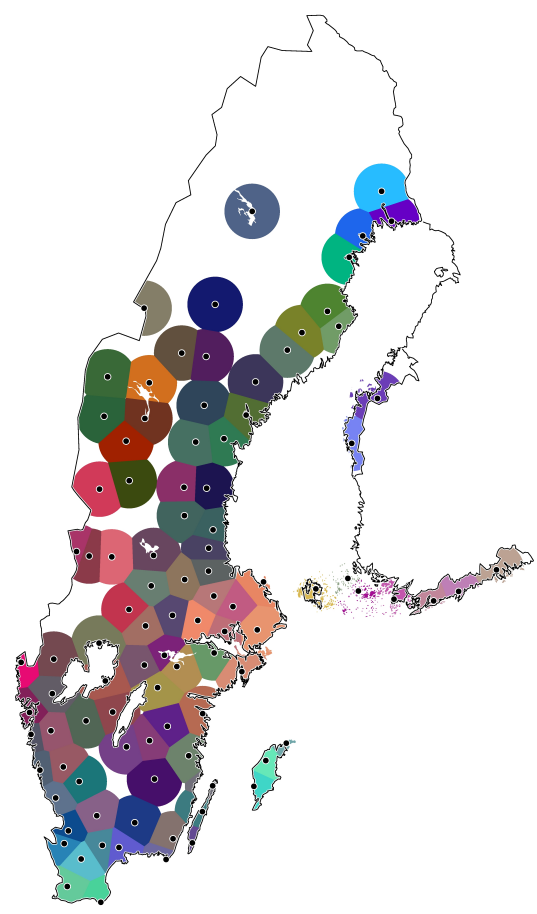

old

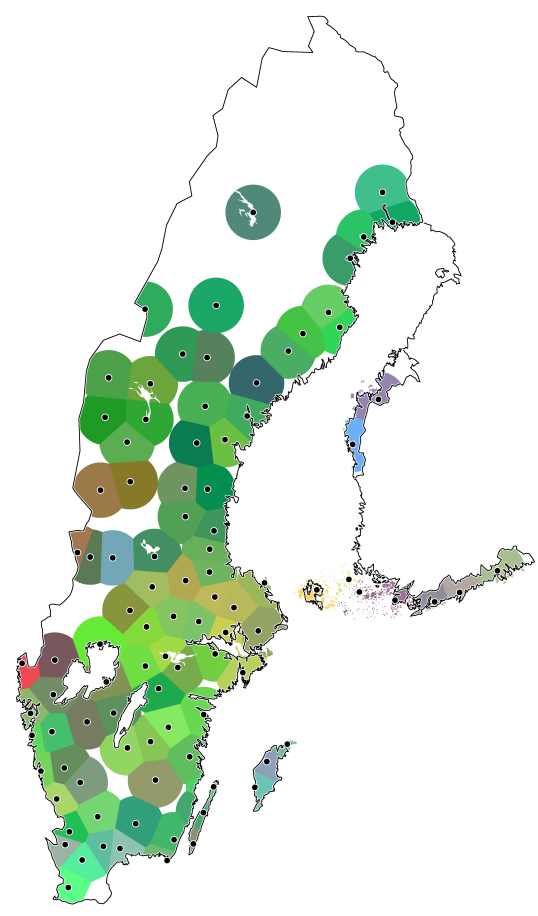

young

FIGURE 5: MDS to 3 dimensions of the linguistic distances between sites and age groups. Both age groups were included in one single MDS analysis, and are represented within the same color spectrum, making the colors of the two maps comparable with each other. 


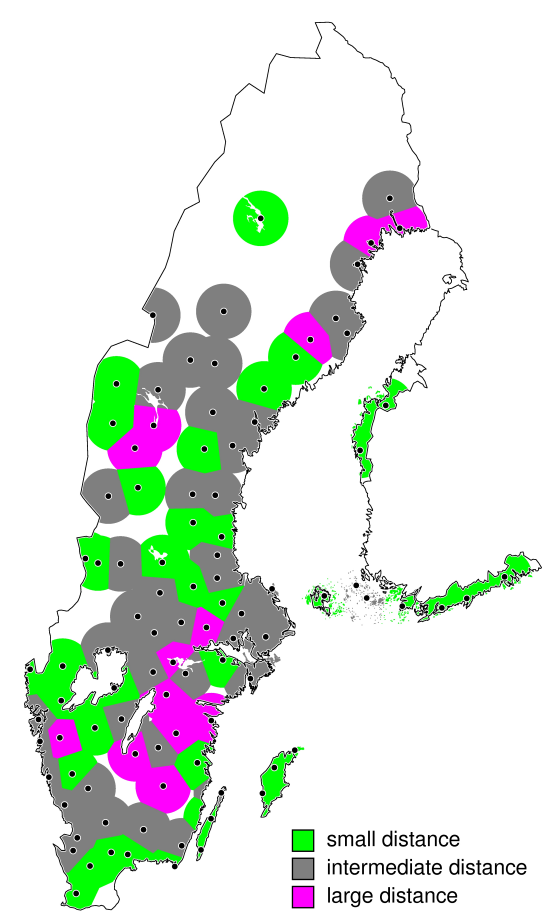

FIGURE 6: Map displaying the aggregate distances between older and younger speakers at each site. The sites were partitioned into three groups by K-means clustering.

Legendre 1998, 349-355). The map in Figure 6 shows the three groups obtained by clustering sites with the most similar distances between the two age groups. All sites with only a relatively small distance between older and younger speakers are green, sites with a large distance are magenta, and the sites with intermediate distances between older and younger speakers are gray.

Dialects in the South Swedish area, on the islands Öland and Gotland, and in Finland are green, and hence have small average distances in vowel pronunciation between older and younger speakers. The same holds for many sites around lake Vänern. These areas seem relatively stable when it comes to vowel pronunciation. Many of the sites close to the two biggest cities, Stockholm and Göteborg, and also in an area south-west from Stockholm are gray or magenta, which suggests a large ongoing change in vowel pronunciation. In Norrland there are sites of all three types: some dialects show a large ongoing change, some an intermediate change, and some are relatively stable.

In the map of the younger speakers in Figure 5 on the preceding page it looks as if there was almost no variation in vowel pronunciation between younger speakers. This is not entirely true. The variation between younger speakers is only so 
much smaller than between older speakers and between the two generations that only a small part of the color spectrum can be used for displaying the differences between younger speakers at different sites.

In order to be able to visualize dialectal differences within the younger age group, MDS was also applied separately to the older and the younger speakers. That is, two separate distance matrices were analyzed, one with the distances between older speakers at all sites and one with the distances between younger speakers at all sites. The analysis of only older speakers included 98 sites and the amount of explained variance was $82.1 \%$ for the first dimension, $93.4 \%$ for two dimensions and $95.7 \%$ for three dimensions. The analysis of only younger speakers included 97 sites (younger speakers in Löderup were left out) and the amount of explained variance was $\mathbf{8 3 . 8 \%}$ for the first dimension, $92.4 \%$ for two dimensions and $96.1 \%$ for three dimensions.

Figure 7 on the facing page shows the maps with results of MDS applied separately to the older and younger speakers. Since two separate analyses are displayed in the two maps, the colors of the maps have to be interpreted independently. The maps are similar to the ones in Figure 5 on page 86, but the colors in each map are more distinct. When the whole color spectrum is used for each age group separately it becomes clear that there are differences across sites among the younger speakers, which could not be distinguished in Figure 5 on page 86 . Moreover, the geographic pattern is quite similar for older and younger speakers. So even if the dialectal differences in vowel pronunciation are larger in the older generation than in the younger, the geographic distribution of dialectal features remains more or less constant.

Some differences in the geographic distributions can also be found. For example, the dialects in Norrland are more coherent in the younger age group than in the older. Figure 6 on the previous page showed that some dialects in Norrland are relatively stable, while others have a large linguistic distance between older and younger speakers. In Norrland the most divergent dialects seem to be changing the most, and thereby a more uniform spoken variety of Norrland is emerging. This can be seen as regionalization of the dialects, since the most divergent dialectal features seem to be disappearing while some other features that distinguish Norrland varieties from other Swedish varieties are preserved.

\section{[5] DISCUSSION AND CONCLUSIONS}

In this paper aggregating techniques were applied to Swedish vowel data in order to investigate geographic relationships in vowel pronunciation and language change in apparent time. The analyses showed that the variation in vowel pronunciation across Swedish dialects is continuous and no abrupt dialect borders exist. The absence of clearly separable dialect groups is in agreement with previous descriptions of the Swedish dialects. In the continuum a number of more 


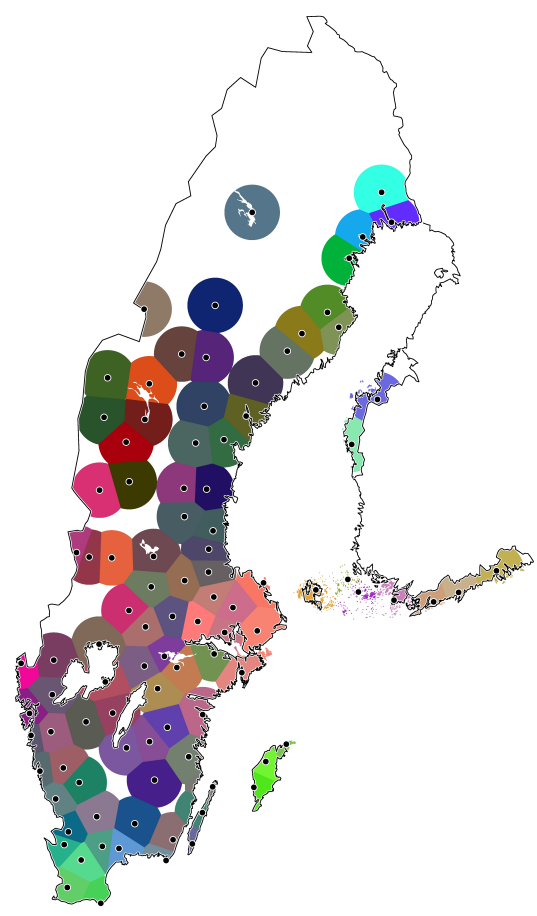

old

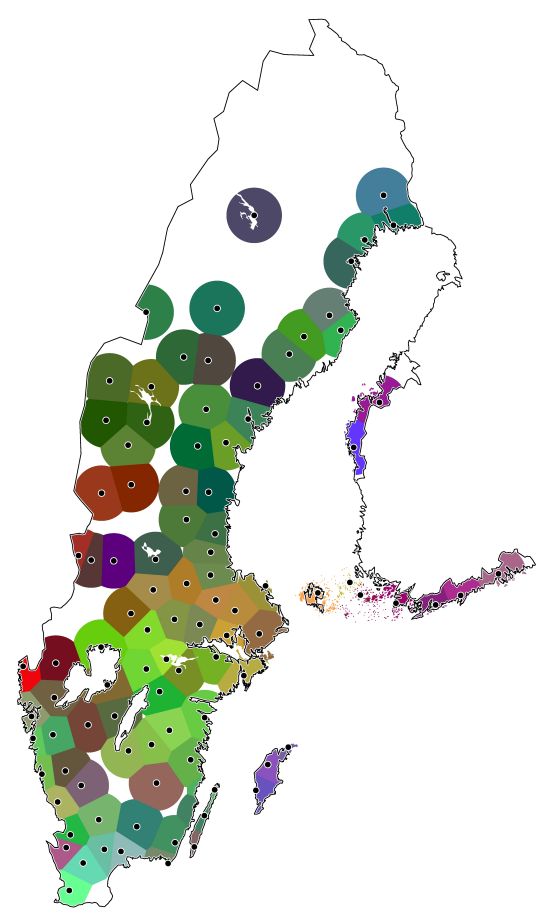

young

FIGURE 7: MDS to 3 dimensions of the linguistic distances between sites for each age group separately. The maps are based on two separate MDS analyses, so that the full color spectrum is used in each of the maps. The colors are not comparable across the two maps. 
coherent dialect areas, separated by gradual transitions, can still be found. One should note that the statistical analyses of the data did not incorporate any geographic information, but purely linguistic data. Still, when interpreted in relation to geography the results show apparent geographical coherence, and the areas that can be detected in the maps displaying the results of multidimensional scaling agree to a large extent with the traditional division of Swedish dialects by Wessén (1969). The main dialect areas-South Swedish, Götaland, Svealand, Gotland, and Finland-can be distinguished in the continuum. Dialects close to the Norwegian border seem to share some features related to vowel pronunciation. The varieties in Finland fall into a Southern group, which shares features with the Svealand dialects, and a Western group. A similar split of the FinlandSwedish dialects was detected in an analysis of intonational variation by Bruce (2004).

The search for isogloss bundles in traditional dialectology has the restriction of being applicable only to geographic variation. One advantage of aggregation is that it "makes sense for many sorts of variation" (Nerbonne 2009). This was shown to be the case in the simultaneous analysis of geographic and age-related variation in Section [4.2] of this paper. The results of MDS show age-related variation mainly on the second dimension, but neither the age-related nor the geographic variation is abrupt but shows a continuous distribution. The analyses show a large-scale ongoing leveling of Swedish dialects. Leveling of the Swedish dialects has been observed by scholars during the latter half of the 20th century. Since leveling has been assumed to concern especially morphological, syntactical and lexical variation, while vowels are presumed to still show considerable dialectal variation, it is striking to find such strong evidence for dialect leveling taking only vowel pronunciation into account. The results also show the persistence of geographic regions. Even if the change in vowel pronunciation is large in some areas, the geographic distribution of dialectal features is not changing much, so that the main dialect areas remain the same even if the linguistic distances between varieties are getting smaller.

Nerbonne (2009) argues that the aggregation and abstraction over a large number of linguistic variables makes it possible to formulate more general characterizations of variation than the analysis of single features allows for. Aggregation gives a more reliable signal of provenance than single features do and makes it possible to identify dialect areas beyond bundles of isoglosses. Aggregation of large data sets also allows us to examine the question whether dialectal variation can best be described in terms of areas or continua. Aggregate analysis has successfully showed the global relationships in vowel pronunciation between the varieties analyzed in this paper. However, a drawback of aggregation is that while focusing on a general level of analysis, the linguistic structure of the variation is not revealed. Areas are detected and the amount of overall change can be mea- 
sured, but questions like how? and why? are not answered. The aggregate analysis does not reveal which linguistic features characterize the dialect areas. For variationist linguists the reasons behind observed changes and geographic distribution patterns are essential since they can be related to historical developments, other expressions of human culture, social relationships and/or linguistic typologies.

In order to give an idea of the variation on the variable level in the present data set, Figure 8 on the following page displays one-standard-deviation ellipses of the 19 Swedish vowels of the older and younger speakers in the PC2/PC1 plane. The data for drawing the ellipses comprised the average PC values of both age groups at each site measured at the temporal midpoint of the vowel segments. By using average values per speaker group for drawing the ellipses, the individual variation within the groups has been filtered out, and the ellipses show the amount of linguistic variation across sites and across the two age groups. The graphs give an idea about the average position of each vowel in the PC space. The size and orientation of the ellipses indicate the amount of variation in each vowel and the main direction of the variation.

The general trend can be seen very clearly in Figure 8 on the next page: except from the leveling of dialects (smaller ellipses with less overlap for younger speakers than for older speakers) there is a general lowering of front vowels going on. Especially the long vowels in dör, lär, lös, nät and söt are being lowered by younger speakers and are thereby filling a place in the vowel space that was not previously filled by any Standard Swedish long vowel phoneme. Of the short vowels included in the data set the vowel in lett shows the most lowering. This lowering of front vowels in Swedish has first been described as a chain shift in the town Eskilstuna by Nordberg (1975). After that the lowering has been attested mainly in cities, for example by Hammermo (1989), Andersson (1994), Kotsinas (1994) and Aniansson (1996). Leinonen (2010) showed that the lowering of front mid-vowels has spread also to a large number of rural Swedish dialects. The areas where the vowel shift is strongest are areas close to and south-west of Stockholm and close to Göteborg, i.e. areas which show a large degree of change on an aggregate level in Figure 6 on page 87 in this paper.

The ongoing chain shift in Swedish front vowels is described in detail by Leinonen (2010). The chain shift can be regarded as simplification of the vowel system: the vowel inventory becomes smaller as allophonic variants of $/ \varepsilon: /$ and / $\varnothing: /$ are disappearing, and also more symmetrical filling up more of the potential vowel space as can be seen in Figure 8 on the next page. According to Kerswill (2002) simplification often occurs during regional dialect leveling. The leveling of Swedish dialects has been confirmed statistically by the aggregate analysis in this paper. The linguistic result of the leveling process, however, can be studied only by analysis on the variable level.

Areas that do not show much aggregate change in vowel pronunciation are 
Long vowels, older speakers

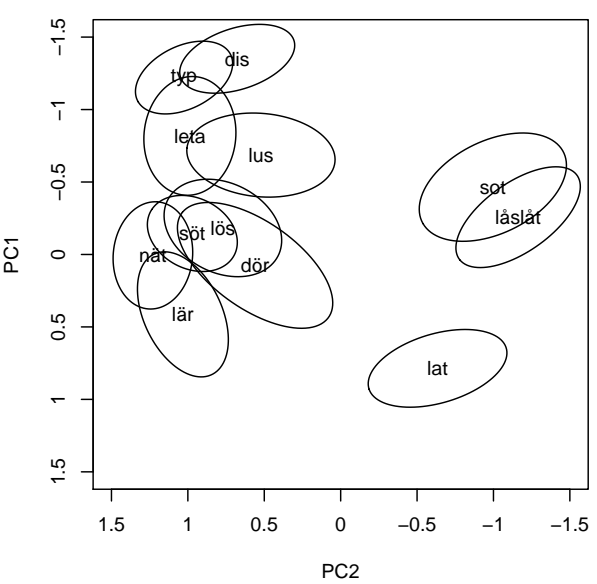

Short vowels, older speakers

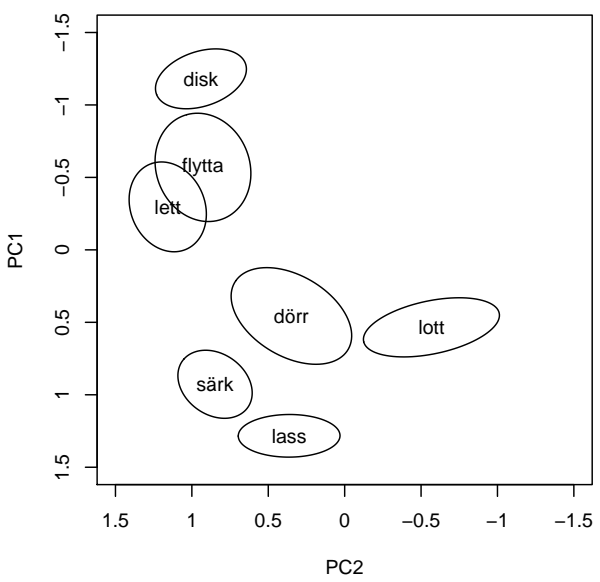

Long vowels, younger speakers

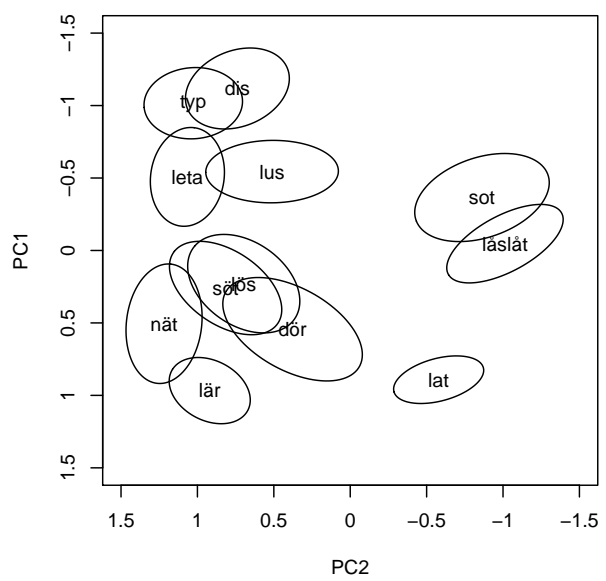

Short vowels, younger speakers

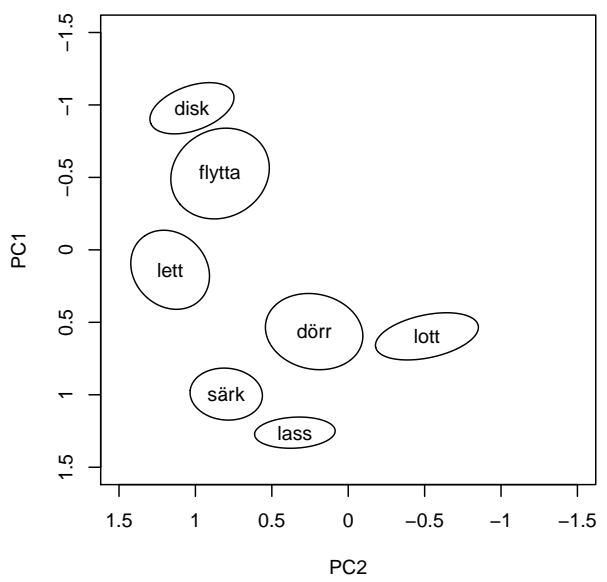

FIGURE 8: The 19 vowels of older and younger speakers in the PC2/PC1 plane. The one-standard-deviation ellipses are drawn based on the average PC values of the two speaker groups at each site measured at the temporal midpoint of each vowel. 
South Sweden (mainly the province Skåne), Gotland and the Swedish dialect area in Finland. Edlund $(2003,28)$ has pointed out that Skåne and Gotland are Swedish regions with a strong regional identity. The identity is enhanced by an awareness of the historical developments that have formed these areas (Skåne was part of Denmark for a long time, while in medieval times Gotland was independent from Sweden and had an important position in the Hanseatic League), and by local traditions and cultural heritage. The Swedish language areas in Finland are separated from the rest of the Swedish dialects not only by the sea and a different political history, but also by a national border. Local identity is manifested through language use, and a strong identity serves to preserve characteristic features in the language.

Aggregation of linguistic data reveals global tendencies and overall relationships between varieties. It serves as a tool for detecting relationships which are not visible in an analysis of single features. For a more comprehensive understanding of linguistic variation, however, aggregate analysis should be complemented by detailed analysis of linguistic structure and extra-linguistic factors. Combining the results of different levels of aggregation and abstraction gives a better understanding of dialectal variation than when using the available methods separately.

\section{REFERENCES}

Andersson, Lars-Gunnar. 1994. Göteborgska - inte alltid så enkelt. In Ulla-Britt Kotsinas \& John Helgander (eds.), Dialektkontakt, språkkontakt och språkförändring i Norden, vol. 40, MINS, 280-290. Stockholm: Institutionen för nordiska språk vid Stockholms universitet.

Aniansson, Eva. 1996. Språklig och social identifikation hos barn i grundskoleåldern. Ph.D. thesis, Uppsala University.

Bruce, Gösta. 2004. An intonational typology of Swedish. In Proceedings of speech prosody 2004, 175-178. Nara.

Bruce, Gösta. 2010. Vår fonetiska geografi. Om svenskans accenter, melodi och uttal. Lund: Studentlitteratur.

Edlund, Lars-Erik. 2003. Det svenska språklandskapet. De regionala språken och deras ställning idag - och i morgon. In Gunnstein Akselberg, Anne Marit Bødal \& Helge Sandøy (eds.), Nordisk dialektologi, 11-49. Oslo: Novus.

Elert, Claes-Christian. 1994. Indelning och gränser inom området för den talade svenskan - en aktuell dialektografi. In Lars-Erik Edlund (ed.), Kulturgränser myt eller verklighet?, vol. 4, DIABAS, 215-228. Institutionen för nordiska språk, Umeå universitet. 
Elert, Claes-Christian. 2000. Allmän och svensk fonetik. Stockholm: Norstedt, 8th edn.

Engstrand, O., R. Bannert, G. Bruce, C.-C. Elert, O. Engstrand \& A. Eriksson. 1997. Phonetics and phonology of Swedish dialects around the year 2000: A research plan. In Rapporter från fonetik 97, den nionde svenska fonetikkonferensen, vol. 4, PHONUM, 97-100. Umeå.

Eriksson, Anders. 2004. SweDia 2000: A Swedish dialect database. In P. J. Henrichsen (ed.), Babylonian confusion resolved. Proceedings of the Nordic symposium on the comparison of languages, vol. 1, Copenhagen Working Papers in LSP, 33-48.

Hallberg, Göran. 2005. Dialects and regional linguistic varieties in the 20th century I: Sweden and Finland. In Oskar Bandle (ed.), The Nordic languages: An international handbook of the history of the North Germanic languages. 2, vol. 22, Handbücher zur Sprach- und Kommunikationswissenschaft, chap. 185, 1691-1704. Berlin: de Gruyter.

Hammermo, Olle. 1989. Språklig variation hos barn i grundskoleåldern. Ph.D. thesis, Uppsala University.

Heeringa, Wilbert. 2004. Measuring dialect pronunciation differences using Levenshtein distance. Ph.D. thesis, University of Groningen.

Jacobi, Irene. 2009. On variation and change in diphthongs and long vowels of spoken Dutch. Ph.D. thesis, University of Amsterdam.

Jain, Anil K. \& Richard C. Dubes. 1988. Algorithms for clustering data. New Jersey: Prentice Hall.

Kerswill, Paul. 2002. Koineization and accommodation. In J. K. Chambers, Peter Trudgill \& Natalie Schilling-Estes (eds.), The handbook of language variation and change, 669-702. Malden, MA: Blackwell.

Kotsinas, Ulla-Britt. 1994. Ungdomsspråk, vol. 25, Ord och stil. Uppsala: Hallgren \& Fallgren.

Legendre, Pierre \& Louis Legendre. 1998. Numerical ecology, vol. 20, Developments in environmental modelling. Amsterdam: Elsevier, 2nd edn.

Leinonen, Therese. 2010. An acoustic analysis of vowel pronunciation in Swedish dialects. Ph.D. thesis, University of Groningen.

Lundberg, Jan. 2005. Classifying dialects using cluster analysis. Master's thesis, Göteborg University. 
Nerbonne, John. 2009. Data-driven dialectology. Language and Linguistics Compass 3(1). 175-198.

Nerbonne, John, Wilbert Heeringa \& Peter Kleiweg. 1999. Edit distance and dialect proximity. In David Sankoff \& Joseph Kruskal (eds.), Time warps, string edits and macromolecules: The theory and practice of sequence comparison, $\mathrm{v}-\mathrm{xv}$. Stanford: CSLI.

Nordberg, Bengt. 1975. Contemporary social variation as a stage in a long-term phonological change. In K.-H. Dahlstedt (ed.), The Nordic languages and modern linguistics 2, 587-608. Stockholm: Almqvist \& Wiksell.

Peterson, Gordon E. \& Harold L. Barney. 1952. Control methods used in a study of the vowels. Journal of the Acoustical Society of America 24. 175-184.

Prokić, Jelena \& John Nerbonne. 2008. Recognizing groups among dialects. International Journal of Humanities and Arts Computing 2(1-2). 153-171.

Tabachnik, Barbara G. \& Linda S. Fidell. 2007. Using multivariate statistics. Pearson, 5th edn.

Thelander, Mats. 2005. Sociolinguistic structures chronologically II: Swedish. In Oskar Bandle (ed.), The Nordic languages: An international handbook of the history of the North Germanic languages. 2, vol. 22, Handbücher zur Sprach- und Kommunikationswissenschaft, chap. 205, 1896-1907. Berlin: de Gruyter.

Tibshirani, Robert, Guenther Walter \& Trevor Hastie. 2001. Estimating the number of clusters in a dataset via the Gap statistic. Journal of the Royal Statistical Society B 63. 411-423.

Wessén, Elias. 1969. Våra folkmål. Stockholm: Fritzes, 9th edn. [first published 1935].

AUTHOR CONTACT INFORMATION

Therese Leinonen

Svenska litteratursällskapet i Finland r.f.

Riddaregatan 5

FIN-00170 Helsingfors

Finland

therese.leinonen@sls.fi 